\title{
Effect of Drought Condition of North Region of Saudi Arabia on Accumulation of Chemical Compounds, Antimicrobial and Larvicidal Activities of Thuja Orientalis
}

\author{
EMAN R. ELSHARKAWY',2 and AHMED M.H.ALI ${ }^{3,4}$ \\ 'Department of Chemistry, Faculty of Science, Northern Border University, Saudi Arabia. \\ ${ }^{2}$ Department of Ecophysiology, Desert Research Center, Mathaf El-Mataria, 15753. Egypt. \\ ${ }^{3}$ Department of Laboratory Sciences, College of Sciences and Arts, Qassim University, Al-Rass, Saudi Arabia. \\ ${ }^{4}$ Department of Zoology and Entomology, Faculty of Science, Assiut University, Egypt. \\ ${ }^{*}$ Corresponding author E-mail: elsharqawyeman2017@gmail.com \\ http://dx.doi.org/10.13005/ojc/350233
}

(Received: December 17, 2018; Accepted: April 01, 2019)

\begin{abstract}
Drought stress and drastic condition of the Northern region of Saudi Arabia especial high temperature in summer season affect widely on the chemical component of plant and its biological actively plant grow in these condition adapt to this stress by accumulation different compound, T. orientalis it is tree grow in garden and farms, when it grows in desert habitat show different content, Gc-Ms analysis of the terpenoid fraction of the plant where it is best fraction given high antimicrobial and Larvicidal activity was done and show the presence of many promising diterpene compounds, Ferruginol, Torulosol, dihydro, 18-Oxo-kauran-17-yl acetate and Andrographolide. The antibacterial testing showed that, the tested gram-positive bacteria exhibited good susceptibility to the terpenoid fraction of methanol extract, which was Staphylococcus epidermidis and Staphylococcus aureus, recorded $13.0 \pm 0.7$ and $11.0 \pm 0.0 \mathrm{~mm}$ inhibition zones, respectively. Indicating promising antibacterial activity against the gram-positive pathogens. While all the tested gram-negative bacteria recorded weak or no susceptibility. The larvicidal activity of plant was studied on Spodoptera littoralis, The lethal concentration was $27.63 \%$ of terpenoid fraction of Thuja orientalis. The plant can considered as a good herbal insecticide instead of synthetic insect side after further studies where the $\mathrm{IC}_{50}$ : Botanical pesticides are highly effective, and ecologically acceptable.
\end{abstract}

Keywords: Thuja orientalis, larvicidal activity, Spodoptera littoralis, Antimicrobial.

\section{INTRODUCTION}

Desert plants are in general did not find the required international interest for many reasons; they are not a potential source for food due to their low density in this harsh conditions, its location in arid zones high in temperature and drought which decrease the interest on them, they low diversity among the vegetation compared with other environments rich in all growth parameters such as water, soil fertility and good climate. However, regarding drugs, desert plants could be unexploded

This is an Open Access article licensed under a Creative Commons license: Attribution 4.0 International (CC- BY). Published by Oriental Scientific Publishing Company @ 2018 
source for bioactive compounds of medicinal importance, this is because desert plants are rich in this bioactive compounds to protect them from this harsh environmental conditions, challenge and competition from soil microorganisms, herbivores and insects which feed on them, also competition between different plant species in desert and tolerance against ecological conditions, drought and high temperature. All these factors lead to production of unique compounds helps in survival of these arid environment.

Spodoptera littoralis (Lepidoptera: Noctuidae), which infests a wide range of economic crops causes critical injuries and loss to cotton, soybean, groundnut, chilli, tobacco, caster, bhendy, tomato and potato'. This pest is widely distributed in Middle East countries and temperate zones in Asia and Africa².

Several methods have been performed to control S. littoralis chemically using synthetic chemical pesticides. Due to the residual toxic effect of these chemicals in the environment, the need for the development of products that not hazardous to the environment can be an alternative strategy for the control of S. littoralis ${ }^{3,4}$. Botanical pesticides hat not hazardous to the environment, are highly effective, and ecologically acceptable ${ }^{5}$.

Thuja orientalis, Cupressaceae family is an evergreen and monoecious tree or shrub evergreen tree, up to 10-20 m high which grows in south and east of Europe, west part of Asia including various parts of Iran. Thuja orientalis has been used in the different activity that is, antipyretic, antitussive, astringent, diuretic, refrigerant and stomachic ${ }^{6}$. (Yeung, 1985). The phyto-constituents of T. orientalis such as flavonoids and terpenoids, coumarine showed high biological activities ${ }^{7}$.

Comparative study between Thuja orientalis plant growing in KSA and Egypt and evaluated its antioxidant and cytotoxic activity, against HCT116, MCF7, PC3, A549 and Hep-G2 cell lines. The essential oil extract from Saudi plant exhibited higher antioxidant activity and cytotoxic activity against deferent cell lines. than the Egyptian plant oil extracts, which is correlated with its high content of some compounds which found in Saudi plant and absence in Egyptian plant ${ }^{8}$.
Thuja occidentalis cones extract contain high levels of bioactive phenolics, flavonoids and other free radical scavengers that can help to control lipid oxidation. This study showed that extract had effective antioxidant activity in raw ground chicken meat during refrigerated storage because use of these extracts inhibited the formation of lipid peroxide and thiobarbituric acid reactive substances in ground chicken meat ${ }^{9}$.

Traditional Plants considered a good source for novel drugs, Owing to their popular use as remedies for many infectious diseases, searches for substances with antimicrobial and insecticidal activity from botanicals source are the main goal for many researchers. This study aimed to select some species form these plants (Thuja orientalis), dominated in the Northern Region according to plant's information and literature, then study It through chemical analyzing and knowing some of its antimicrobial properties and the the bioactivity of plant extract against the larva of S. littoralis. Which provide basic necessary information to explore the properties of this plant in this area, which are not studied adequately, and give a picture about the role of environment on the accumulation of chemical compounds to adapt the desert condition.

\section{MATERIAL AND METHODS}

\section{Plant Material}

Plant Thuja orientalis were collected from wild population from Arar region, Northern Region, Saudi Arabia in March 2018 the Authentic sample was identified and deposited in Faculty of science girl section.

\section{Extraction}

The air-dried powdered leaves (500 g) of Thuja orientalis were subjected to successive extraction with $\mathrm{CHCl}_{3}$ using a Soxhlet apparatus. The $\mathrm{CHCl}_{3}$ extract $(38.00 \mathrm{~g})$ was dissolved in a suitable amount of hot distilled $\mathrm{H}_{2} \mathrm{O}-\mathrm{MeOH}$ (95:5 $\mathrm{v} / \mathrm{v}, 200 \mathrm{~mL}$ ), then partitioned between petroleum ether and $\mathrm{CHCl}_{3}$. The petroleum ether $(20.50 \mathrm{~g})\{\mathrm{C} 1)$ and $\mathrm{CHCl}_{3}(17.10 \mathrm{~g}, \mathrm{C} 2)$ fractions were individually concentrated under reduced pressure and kept for biological analysis. 


\section{Fractionation of the $\mathrm{CHCl}_{3}$ Fraction}

The $\mathrm{CHCl}_{3}$ fraction was subjected to silica gel column chromatography $(550 \mathrm{~g}$, mesh size $0.063-0.200 \mathrm{~mm}$, Merck) $(150 \mathrm{~cm} \times 3 \mathrm{~cm}$ i.d.) eluted with $\mathrm{n}$-hexane, gradually increasing the polarity with EtOAc, which resulted in the isolation of terpenoid fraction (C2)which were subjected to analyzed with GC-MS.

\section{GC-MS analysis}

The compounds were analyzed using a Thermo GC-Trace ultra system (Thermo Co. USA), they were separated on $30 \mathrm{~m}$ X0.25 mm X $0.25 \mu \mathrm{m}$ Elite-5MS column (Thermo Scientific GC Column). The column temperature was increased from $40^{\circ} \mathrm{C}$ to $220^{\circ} \mathrm{C}$ at a rate of $4^{\circ} \mathrm{C} / \mathrm{min}$; injector temperature, $250^{\circ} \mathrm{C}$; injection volume, $1 \mu \mathrm{l}$; helium carrier gas flow rate $20 \mathrm{ml} / \mathrm{min}$; transfer temperature, $280^{\circ} \mathrm{C}$. MS parameters were as follows: El mode, with ionization voltage $70 \mathrm{ev}$, ion source temperature, $180^{\circ} \mathrm{C}$; scan range, 50-600 $\mathrm{Da}$. The peaks were tentatively identified based on library search using NIST and Wiley Registry 8 Edition .

\section{Insects}

laboratory strain of S. littoralis was reared in the laboratory at $26 \pm 2^{\circ} \mathrm{C}$ and $65 \pm 5 \%$ R.H., with 8:16 L:D h photoperiod. Larvae were fed on fresh castor leaves, Ricinus communius. The experiments were performed on the $4^{\text {th }}$ instar larvae.

\section{Insecticidal Bioassay}

The determination of the lethal concentration values (LC30; LC50; LC90) of the Thuja orentalis against the $4^{\text {th }}$ larval instar of S. littoralis was evaluated by leaf dipping technique method. Five concentrations $(10,15,20,30$, and $40 \%)$ of the Thuja orentalis were used. Equal discs of fresh castor bean leaves were dipped in each tested concentrations of the extract for a while and left to dry. Ten starved larvae were transferred into each cup and allowed to feed on the treated and untreated leaves. Five replicates for each concentration were performed. Mortality counts were evaluated $24 \mathrm{~h}$ post-treatment and corrected according to Abbott (1925) ${ }^{10}$.

\section{Antibacterial activity}

The antibacterial potential of the leaves of Thuja orientalis was evaluated using the disc diffusion method as mentioned in,(Elsharkawy et al.,2018) ${ }^{8}$ with slit modifications. Dr. Fiaz Ahmed generously provided pathogenic bacterial strains (2 gram-positive and 3 gram-negative bacteria) from the pathology lab, Al-Rass Hospital, Saudi Arabia. Bacterial strains were sub-cultured in blood agar plates for $24 \mathrm{~h}$ and $37^{\circ} \mathrm{C}$. the plant extract was reconstituted in absolute methanol (not lethal for bacteria) to get a concentration $500 \mathrm{mg} / \mathrm{ml}$. For disc diffusion method, a single colony was transferred to a sterile tube containing $100 \mu \mathrm{l}$ normal saline $(0.9 \%)$ and diluted to get a turbidity equivalent to 0.5 McFarland standard $(1 \times 108 \mathrm{cfu} / \mathrm{mL}) .100 \mu$ of that suspension was spread over previously prepared Mueller Hinton agar plate, then, covered and left for a while. Sterile paper discs (size $6 \mathrm{~mm}$ ) were cut from Whatman filter paper (No.1) and immersed in the reconstituted extract and then loaded over the inoculated plates. Another paper disc saturated with chloramphenicol solution $(5 \mathrm{mg} / \mathrm{ml})$ was loaded on the plate to act as a positive control. All plates were incubated at $37^{\circ} \mathrm{C}$ for up to 24 hour. The diameter of inhibition zones (in $\mathrm{mm}$ ) was measured and the mean was calculated from two replicates.

\section{RESULTS AND DISCUSSION}

GC-MS analysis of chloroform fraction of plant Thuja orientalis revealed the existence of diterpene compounds, Ferruginol, Andrographolide, Torulosol, dihydro, 18-Oxo-kauran-17-yl acetate and of ent-16-Hydroxy-17-acetoxy-19-kauranal, Other non terpenoid compound also detected in chloroform fraction, Cymarin and K-Strophanthin, cardic glycoside type. the results are shown in Table 1.

The antibacterial of active diterpene types isolated from Chamaecyparis lawsoninana have modulator activity against multi drug resistance of Staphylococcus aureus, S. aureus strains and two epidemic methicillin-resistant, clinical isolates. ferruginol, pisiferol and its epimer 5-epipisiferol, formosanoxide, trans-communic acid and torulosal, Some of these compounds also exhibited modulatory activity in potentiating antibiotic activity against effluxing strains and ferruginol, used at a subinhibitory concentration, resulted in an 80-fold potentiation of oxacillin activity against strain EMRSA-15. An efflux inhibition assay using an $S$. aureus strain possessing the MDR NorA efflux pump resulted in $40 \%$ inhibition of ethidium bromide efflux at $10 \mathrm{microM}$ ferruginol $(2.86 \mathrm{microg} / \mathrm{ml})^{11}$. (Smith et al., 2007), this come in harmony with 
current study where ferruginol and torusolal are detected in diterpene fraction of the plant in high amount.

Table 1: Major compounds of chloroform fraction of leaves of Thuja orientalis

\begin{tabular}{|c|c|c|c|c|}
\hline & Compounds & $\%$ & $\mathrm{RI}$ & Molecular Formula \\
\hline 1 & Andrographolide & 1.6 & 1005 & $\mathrm{C}_{20} \mathrm{H}_{30} \mathrm{O}_{5}$ \\
\hline 2 & $\begin{array}{l}\text { ent-16 } \alpha \text {-hydroxy- } \\
\text { 17-acetoxy-19-kauranal }\end{array}$ & 1.4 & 1934 & $\mathrm{C}_{22} \mathrm{H}_{34} \mathrm{O}_{4}$ \\
\hline 3 & $\begin{array}{l}3 \alpha \text {-Acetyloxy- } \\
5 \alpha \text {-pregnan-20-one }\end{array}$ & 0.15 & 1050 & $\mathrm{C}_{23} \mathrm{H}_{36} \mathrm{O}_{3}$ \\
\hline 4 & alpha.-D-Glucopyranose & 0.24 & 1404 & $\mathrm{C}_{6} \mathrm{H}_{12} \mathrm{O}_{6}$ \\
\hline 5 & $\begin{array}{l}\text { 18-Oxo-kauran- } \\
\text { 17-yl acetate }\end{array}$ & 0.35 & 1980 & $\mathrm{C}_{22} \mathrm{H}_{34} \mathrm{O}_{3}$ \\
\hline 6 & Torulosol, dihydro & 2.5 & 1200 & $\mathrm{C}_{20} \mathrm{H}_{36} \mathrm{O}_{2}$ \\
\hline 7 & Ferruginol & 5.5 & 2225 & $\mathrm{C}_{20} \mathrm{H}_{30} \mathrm{O}$ \\
\hline 8 & Benzoic acid & 5.2 & 1697 & $\mathrm{C}_{7} \mathrm{H}_{6} \mathrm{O}_{2}$ \\
\hline 9 & Dihydro-coumarone & 0.3 & 1036 & $\mathrm{C}_{8} \mathrm{H}_{8} \mathrm{O}$ \\
\hline 10 & $\begin{array}{l}\text { Chromone-hydroxy6,7,8- } \\
\text { trimethoxy-2,3-dimethyl }\end{array}$ & 0.11 & 2250 & $\mathrm{C}_{14} \mathrm{H}_{16} \mathrm{O}_{6}$ \\
\hline 11 & $\begin{array}{l}\text { Card-20(22)-enolide, } \\
\text { 3-[(2,6-dideoxy-3-O- } \\
\text { methyl-.beta.-D-ribo- } \\
\text { hexopyranosyl)oxy]-5, } \\
\text { 14-dihydroxy-19-oxo-, } \\
\text { [Cymarin] }\end{array}$ & 26.94 & 4191 & $\mathrm{C}_{30} \mathrm{H}_{44} \mathrm{O}_{9}$ \\
\hline 12 & $\begin{array}{l}\text { Card-20(22)-enolide, } \\
\text { 3-[(2,6-dideoxy-4-O-. } \\
\text { beta.-D-glucopyranosyl- } \\
\text { 3-O-methyl-.beta.-D-ribo } \\
\text {-hexopyranosyl)oxy]-5, } \\
\text { 14-dihydroxy-19-oxo- } \\
\text { [K-Strophanthin] }\end{array}$ & 2.25 & 5558 & $\mathrm{C}_{36} \mathrm{H}_{54} \mathrm{O}_{14}$ \\
\hline
\end{tabular}

\section{Antibacterial properties}

The evaluation of the antibacterial activity of the chloroform fraction of methanolic extract of Thuja orental leaves are represented in Fig. 1,2 and Table 2. As shown from the results, only the gram-positive were susceptible to the plant extract while the gram-negative bacteria showed very weak or no susceptibility against the extract. The tested gram-positive bacteria recorded $13.5 \pm 0.7 \mathrm{~mm}$ for Staphylococcus epidermidis and $11.0 \pm 0.0 \mathrm{~mm}$ for Staphylococcus aureus, respectively. Where as, the tested gram-negative bacteria recorded $6.5 \pm 0.7 \mathrm{~mm}$ for Klebsiella pneumoniae and Escherichia coli and $6.0 \pm 0.0 \mathrm{~mm}$ for Acinitobacter baumannii, putting in consideration that the blank disc diameter is $6.0 \mathrm{~mm}$. The antibiotic, chloramphenicol $(5 \mathrm{mg} / \mathrm{ml})$ was used as a positive control. The noticeable antibacterial activity of the methanol extract of the leaves of Thuja orental against Staphylococcus epidermidis and Staphylococcus aurerus in the current study is attributed to some bioactive phytochemical constituents present in this aromatic plant. Plants are rich source of alternative antibacterial copounds able to combat the growing phenomenon of antibiotics resistant bacteria ${ }^{12}$. The finding of the current study is in agreement with previous studies on the antibacterial activity, in general. Duhan et al., 2013 ${ }^{13}$, cited that the methanol, acetone and ethyl acetate extracts of Thuja orental leaves were found effective against various gram-negative and gram-positive bacteria (i.e. Staphylococcus aureus, Bacillus subtilis, Pseudomonas aeruginosa, Alcaligenes faecalis and Klebsiella pneumoniae) and were mostly competitor to some antibiotics. Kshirsagar et al., ${ }^{14}$, mentioned that, the acetone, ethyl acetate and methanol extracts of Thuja orentalis leaves where tested against different bacterial strains. Only methanol and acetone extracts recorded highest antibacterial efficacy, particularly against Bacillus subtilis. Moreover, Jain and Grag $1997^{15}$ reported significant antibacterial activity of the essential oils of Thuja orental against all tested gram-positive and gram-negative bacteria, especially S. typhi. Accordingly, more future studies should be conducted on this plant particularly its aromatic compounds, which could be used in the formulation of new natural antibacterial agents.

Table 2: Antibacterial activity of chloroform fraction of Thuja orentalis leaves compared with the antibiotic (Chloramphenicol)

\begin{tabular}{lccccc}
\hline Tested & \multicolumn{5}{c}{ Zone of Inhibition $(\mathrm{mm})$} \\
\hline & Sa & Se & Ab & Kp & Ec \\
Extract & $11.0 \pm 0.0$ & $13.5 \pm 0.7$ & $6.0 \pm 0.0$ & $6.5 \pm 0.7$ & $6.5 \pm 0.7$ \\
$(500 \mathrm{mg} / \mathrm{ml})$ & & & & & \\
$\begin{array}{l}\text { Chloramphenicol } \\
(5 \mathrm{mg} / \mathrm{ml})\end{array}$ & $25.5 \pm 0.7$ & $27.0 \pm 0.0$ & $21.0 \pm 1.4$ & $26.5 \pm 0.7$ & $29.5 \pm 0.7$ \\
\hline
\end{tabular}

$\mathrm{Sa}=$ Staphylococcus aureus, $\mathrm{Se}=$ Staphylococcus epidermidis, $\mathrm{Ab}=$ Acinitobacter baumannii, $\mathrm{Ec}=$ Escherichia coli, $\mathrm{Kp}=$ Klebsiella pneumonia Zone diameter equal 6 $\mathrm{mm}=$ no inhibition, mean \pm standard deviation. 


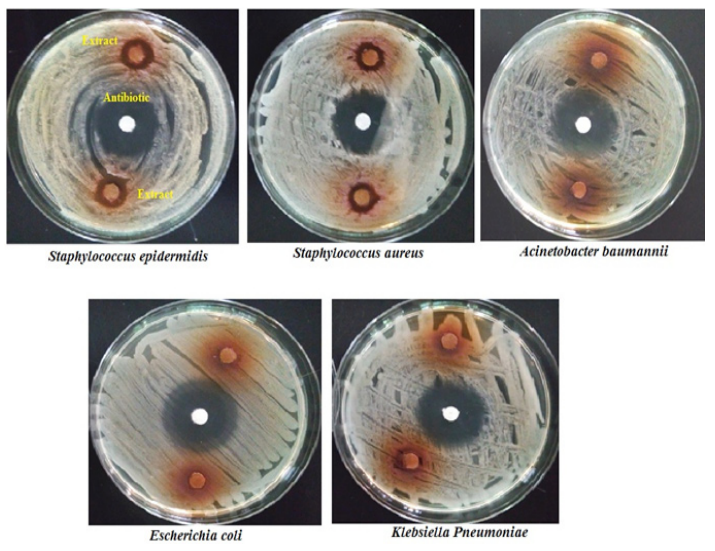

Fig. 1. Representative photo showing susceptibility of S. epidermidis and S. aureus to the chloroform fraction

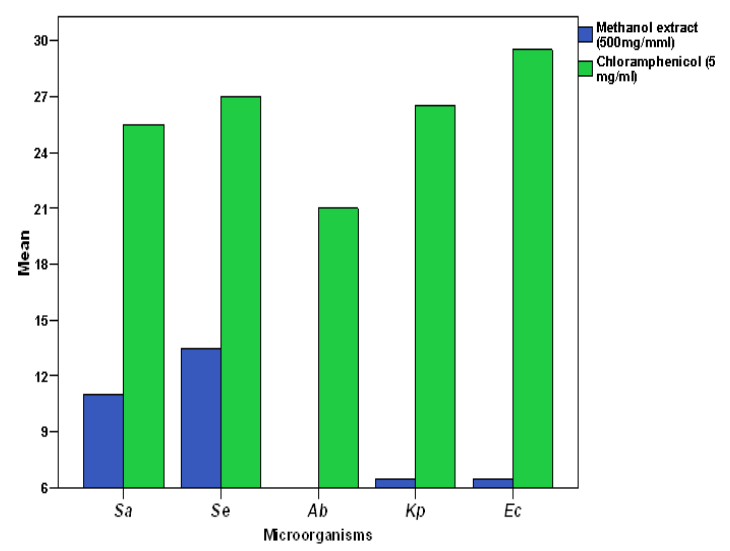

Fig. 2. Antibacterial activity of the chloroform fraction of Thuja orentalis leaves using disc diffusion test

\section{Insecticidal activity}

Insecticidal activity of Thuja orentalis was calculated based on larval mortality after treatment. According to the $\mathrm{LC}_{50}$ values of the fraction, the present results indicated that Thuja orentalis have larvicidal activity against $4^{\text {th }}$ instar larvae of S. littoralis as was shown in Table 3 .

Table 3: Susceptibility of the $4^{\text {th }}$ instar larvae of S. littoralis to Thuja orientalis

\begin{tabular}{|c|c|c|c|c|}
\hline \multirow[t]{2}{*}{ Plant } & \multicolumn{2}{|c|}{$\begin{array}{c}\text { Lethal } \\
\text { concentrations (\%) }\end{array}$} & \multicolumn{2}{|c|}{$\begin{array}{c}95 \% \text { confidence limits } \\
\text { for concentrations }\end{array}$} \\
\hline & & & Lower & Upper \\
\hline \multirow[t]{3}{*}{ Thuja orentalis } & $\mathrm{LC}_{30}$ & 22.74 & 21.37 & 24.04 \\
\hline & $\mathrm{LC}_{50}$ & 27.63 & 26.17 & 29.26 \\
\hline & $\mathrm{LC}_{90}$ & 44.48 & 40.74 & 49.86 \\
\hline
\end{tabular}

$\mathrm{LC}_{30}$ - Lethal concentration that kills $30 \%$ of the exposed larvae, $\mathrm{LC}_{50}$ - Lethal concentration that kills $50 \%$ of the exposed larvae, $\mathrm{LC}_{90}$ - Lethal concentration that kills $90 \%$ of the exposed larvae
Little know about the effects of plant metabolites on the biology of $S$. littoralis. terpenoid and cardiac glycoside, considered as secondary metabolites synthesized by desert plants with physical and biochemical properties. Hexane extract of was found to have antimicrobial and larvicidal properties against Aedes aegypti larva, chromatographic separation of the extract leading to the isolation of five Kaurane diterpene as the major compounds, this agree with present study, where the diterpene fraction contain 18-Oxo-kauran-17-yl acetate and kuran 19-ol-acetate, two type of kauran ${ }^{16}$.

Andrographolide compound show antifedent activity against fourth instar larvae of Papilo demoleus at concentration of $200 \mathrm{ppm}$ and it was recommended to use as a pest control against Papilo demoleus ${ }^{17}$. The use of plants as larvicidals agents are very useful and can be used as substitute against pesticides.

\section{CONCLUSION}

Plant Thuja orentalis is medicinal plant used for antipyretic, antitussive, astringent, diuretic current study was aimed to study the role of plant as a herbal insecticide and bactericide instead of synthetic drugs, and role of chemical composition of the plant on these biological activity, Gc-Ms analysis reflect the presence of diterpene compounds as major compound in chloroform fraction, many promising compound, which have antimicrobial and larvicidal activity was detected, Ferruginol, Torulosol, dihydro, 18-Oxo-kauran-17-yl acetate and Andrographolide. Insecticidal activity of Thuja orentalis was calculated based on larval mortality after treatment. According to the $\mathrm{LC}_{50}$ values of the tested products, the present results indicated that Thuja orentalis have larvicidal activity against $4^{\text {th }}$ instar larvae of $S$. littoralis, also have good antimicrobial activity against gram-positive bacteria while all the tested gram-negative bacteria recorded weak or no susceptibility. we can concluded that plant Thuja orentalis have a potent activity as a larvicidal and microbial activity.

\section{ACKNOWLEDGMENT}

The author gratefully acknowledgment the approval and support of this research by the grant no: SCl-2017-1-8-F-7417 from the deanship of Scientific Research of Northern Border University, Arar, Saudi Arabia.

\section{Conflict of Interest}

The authors declare any conflict of interest 


\section{REFERENCES}

1. Ferry N, Edwards MG, Gatehouse AMR. Plantinsect interaction: Molecular approaches to insect resistance. In: Biotechnology (Eds.: T. Sasaki and P. Christou)., 2004, 15, 155-161.

2. Salama, H. S.; Salem, S. A.; Zaki, F. N. and Shams EL-din, A. (1990): Comparative effectiveness of Bacillus thuringiensis and lannate against Spodoptera littoralis. J. Islam. Acad. Sci., 19903, 4, 325-329.

3. Nakata, H.; Hirakawa, Y.; Kawazo, M.; Nakabo, T.; Arizono, K.; ABE, S. I.; Kitano, T.; Shimada, H.; Watanabe, I.; LI, W.; Ding, X. Concentrations and compositions of Organochlorine contaminants in sediments, soils, crustaceans, fishes and birds collected from Lake Tai, Hangzhou Bay and Shangai city region. China Environmental Poly., 2005, 133, 415-429.

4. Pavela, R.; Vrchotova, N.; ERA, B. Growth inhibitory effect of extracts from Reynoutria sp. plants against Spodoptera littoralis larvae. Agrociencia (Montecillo)., 2008, 42(5), 573-584.

5. Senthil Nathan, S. and Kalaivani, K. Efficacy of nucleopolyhedrovirus (NPV) and azadirachtin on Spodoptera litura Fabricius (Lepidoptera :Noctuidae). Biological Control., 2005, 34, 93-98.

6. Young. Him-Ch. Handbook of Chinese herbs and formulas Instute of Chinese Medicine., Los Angeles., 1985.

7. Sridhar S. R., Rajagopal R. V., Rajavel R., Masilamani S., and Narasimhan S. Antifungal activity of some es sential oils. J. Agric. Food Chem., 2003, 51, 7596D 7599.

8. Elsharkawy ER, Ed-dra A, Abdallah EM, Ali AM. Antioxidant, antimicrobial and antifeedant activity of phenolic compounds accumulated in Hyoscyamus muticus L. African Journal of Biotechnology., 2018, 17(10), 311-321.

9. Yogesh K. and Jamshed A. Antioxidant potential of (Thuja occidentalis) cones and peach (Prunus persia) seeds in raw chicken ground meat during refrigerated $\left(4 \pm 1^{\circ} \mathrm{C}\right)$ storage, Food Sci Technol., 2014, 51(8), 1547-1553.

10. Abbott, W. S. A method of computing the effectiveness of an insecticide. Journal of Economic Entomology., 1925, 18, 265-267.

11. Smith ECJ, Williamson EM, Wareham N, Kaatz GW, Gibbons S. Antibacterials and modulators of bacterial resistance from the immature cones of Chamaecyparis lawsoniana. Phytochem., 2007, 68(2), 210-217.

12. Abdallah EM. Plants: An alternative source for antimicrobials. Journal of Applied Pharmaceutical Science., 2011, 1(6), 16-20.

13. Duhan JS, Saharan P, Surekha A. Phytochemical analysis and antimicrobial potential of leaf extracts of Thuja orientalis. Asian Journal of Pharmaceutical and Clinical Research., 2013, 6(2), 291-294.

14. Kshirsagar S, Malode S, Bansode S. Pharmacological activities of Thuja orientalis Linn. International Journal of Pharmacognecy., 2018, 5(6), 331-336.

15. Jain RK, Grag SC . Antimicrobial activity of the essential oil of Thuja orental L. Ancient science of Life., 1997, I3, 186 - 189.

16. Dayanne MS, Emmanoel VC, Paulo C. L, Nogueira Valéria R. , Souza M. ent-Kaurane diterpenoids and other constituents from the stem of Xylopia laevigata (Annonaceae), Quim. Nova., 2012, 35(8), 1570-1576.

17. Vattikonda, S. R. Effect of andrographolide on feeding behaviour of Papilio demoleus L., (Lepidoptera: papilionidae) larvae. Asian J. Bio. Sci., 2015, 10(1), 65-70. 